\title{
ESTUDO ACERCA DO DIREITO DE REGRESSO NO CONTRATO DE FACTORING NA JURISPRUDÊNCIA DO STJ
}

\author{
STUDY ABOUT THE RIGHT TO THE FACTORING CONTRACT IN CASE \\ LAW STJ \\ ${ }^{1}$ Leandro Moraes do Espírito Santo
}

\section{RESUMO}

Este ensaio visa analisar o direito de regresso no contrato de fomento mercantil na jurisprudência do Superior Tribunal de Justiça. A fim de chegar a uma resposta adequada, o trabalho investiga o problema a partir dos ensinamentos de Hans Kelsen para teoria do direito e dos elementos de interpretação jurídica adotados no ordenamento jurídico brasileiro.

Palavras-chave: Factoring, Direito de regresso, teoria do direito

\begin{abstract}
This essay aims to examine the right of recourse in commercial development contract in the case law of the Supreme Court. In order to reach an appropriate response, the paper investigates the problem from Hans Kelsen's teachings to theory of law and legal interpretation as may be adopted in the Brazilian legal system.
\end{abstract}

Keywords: Factoring, Right of return, legal theory

\footnotetext{
${ }^{1}$ Mestrando em Direitos Fundamentais pela Universidade da Amazônia, -UNAMA, Pará, PA.(Brasil). Professor na Universidade Federal do Pará - UFPA, Pará, PA.(Brasil) E-mail: leandromoraes1410@ gmail.com.
} 


\section{INTRODUÇÃO}

O factoring é um contrato que demanda maior atenção, tendo em vista que o número de empresários exercendo a atividade de fomento mercantil tem aumentado e o número de transações formalizadas por meio do referido contrato, atendendo principalmente micro e pequenos empresários, acompanhou o crescimento. ${ }^{1}$

Conforme as operações de factoring foram crescendo, proporcionalmente surgiram dúvidas acerca da natureza, conceito, regulamentação e tratamento jurídico para dirimir conflitos provenientes das operações.

Dentre as principais questões que encabeçam as demandas acerca do contrato de factoring, temos a possibilidade ou não de direito de regresso do faturizador contra o faturizado. Na sua jurisprudência o Tribunal da Cidadania vem se posicionando contra a possibilidade de direito de regresso no contrato de factoring. Divergências na doutrina e na jurisprudência surgem constantemente, ainda que conste no contrato a possibilidade de o faturizador exercer este direito.

Este será o objeto de estudo deste trabalho. Esta pesquisa, portanto, é relevante e atual e importante para refletir aspectos de teoria do direito que devem ser considerados no momento de decidir.

Nessa linha de raciocínio, este estudo visa investigar num plano teórico e jurídico, se o Superior Tribunal de Justiça vem respeitando as premissas da teoria do direito, particularmente, no problema apresentado.

Para chegarmos a uma resposta adequada optamos por fazer uma pesquisa que adotou a vertente jurídico-teórica, que conforme Witker (1985, apud DIAS; GUSTIN, 2002, p. 22):

[...] acentua os aspectos conceituais, ideológicos e doutrinários de determinado campo que se deseja investigar [...] deverá seguir os mesmos passos das demais, à exceção dos procedimentos metodológicos das pesquisas de campo. Isso não significa, porém, que as investigações inseridas nessa vertente

\footnotetext{
${ }^{1}$ A Anfac - Associação nacional de fomento comercial apontou que em 2011 que o setor movimentou 85 bilhões de reais, conforme levantamento do Serasa Expirian. Notícia disponível em: <http://www.anfac.com.br/v3/informativos-noticias.jsp?id=689> acesso em 02/01/2016. Sobre o crescimento do volume de negócios no setor, ver também: http://oglobo.globo.com/economia/governo-vai-criar-regras-para-empresas-de-factoring-6665149 acesso em 02/01/2016.
}

Revista Brasileira de Direito Empresarial| e-ISSN: 2526-0235| Brasília | v. 2 | n. 1 | p. 115-132 | Jan/Jul 2016. 
não tenham natureza aplicada como as demais, visto que toda investigação no campo das ciências sociais aplicadas, deve visar uma aplicação prática, mesmo que não imediata.

Trata-se de investigação jurídico-exploratória, que permite uma abordagem preliminar de um problema jurídico, ressaltando características percepções e descrições, podendo abrir caminhos para outras pesquisas mais profundas e com hipóteses mais precisas (WITKER, 1985 apud DIAS; GUSTIN, 2002).

Assim, apresentaremos o conceito do contrato de factoring, sua natureza jurídica, as suas modalidades e as principais características, com enfoque para o factoring convencional, por ser este, sem dúvida, o que é mais praticado no Brasil.

Exporemos as principais correntes existentes na doutrina no que tange a possibilidade do direito de regresso nos contratos de factoring. Apontaremos também as recentes decisões do STJ e as confrontaremos com aspectos da teoria do direito, particularmente noções da teoria desenvolvida por Hans Kelsen, bem como com os elementos de interpretação jurídica que devem ser considerados numa decisão.

\section{O CONTRATO DE FACTORING}

O factoring, fomento mercantil, fomento empresarial ou faturização, é um contrato complexo que se aperfeiçoa pela aquisição remunerada de créditos, cumulando também com a prestação de serviços. Num pólo da relação contratual encontra-se o faturizador (o adquirente dos créditos e/ou prestador de serviços), e noutro pólo encontra-se o faturizado (aquele que vende os créditos e/ou contrata os serviços), conforme a brilhante lição de Fabrício Vasconcelos de Oliveira (2006) ${ }^{2}$.

Entretanto, na doutrina existem juristas que limitam o contrato de factoring apenas à transmissão (por meio de cessão ou endosso) remunerada de créditos

\footnotetext{
2 “[...] entendemos a faturização como o contrato que envolve a transferência de créditos cumulada com a prestação de serviços (convencionais ou diferenciados) por parte de uma pessoa a outra. A pessoa que transfere os créditos e recebe os serviços é denominado faturizado e aquele que adquire os créditos e presta os serviços, faturizador ou factor" (OLIVEIRA, 2006, p. 91)
} 
oriundos de vendas a prazo realizadas pelo faturizado, sendo, portanto, um contrato intimamente ligado à emissão e venda de faturas (DINIZ, 2011) ${ }^{3}$.

O factoring não está disciplinado no Código Civil e em nenhuma outra lei. Tratase de contrato atípico, cabível no Brasil, pelo disposto no art. 425 do Código Civil, que prescreve: "é lícito as partes estipular contratos atípicos, observadas as normas gerais fixadas neste código".

Sobre a definição de contrato atípico, importante mencionar a doutrina de Álvaro Villaça Azevedo (2002, p. 132):

Os contratos típicos recebem do ordenamento jurídico uma regulamentação particular, e apresentam-se com um nome, ao passo que os atípicos, embora possam ter um nome, carecem de disciplina particular, não podendo a regulamentação dos interesses dos contratantes contrariar a lei, a ordem pública, os bons costumes e os princípios gerais de direito.

Assim, temos apenas a conceituação da atividade de fomento mercantil para fins de tributação de imposto de renda das pessoas jurídicas, apresentada pelo Artigo 15, parágrafo $1^{\circ}$, III, d, da Lei 9249/95, que diz ser o factoring:

Prestação cumulativa e contínua de serviços de assessoria creditícia, mercadológica, gestão de crédito, seleção de riscos, administração de contas a pagar e a receber, compra de direitos creditórios resultantes de vendas mercantis a prazo ou de prestação de serviços (factoring).

Acerca dos conceitos até então apresentados, mister mencionar que está em tramitação no Congresso Nacional o PLC $n^{\circ}$. 13/2007, que tem a finalidade de disciplinar o contrato de factoring. Nesse sentido o conceito disposto no artigo $2^{\circ}$ do Projeto acima citado:

Art. $2^{\circ}$ Contrato de fomento empresarial é aquele pelo qual uma parte transmite à outra, total ou parcialmente, a título oneroso, créditos decorrentes de suas atividades empresariais.

\footnotetext{
"O contrato de faturização de fomento mercantil ou factoring é aquele em que um empresário (faturizado) cede a outro (faturizador), no todo ou em parte, os créditos provenientes de suas vendas mercantis a terceiro, mediante o pagamento de uma remuneração, consistente no desconto sobre os respectivos valores, ou seja, conforme o montante de tais créditos. É um contrato que se liga à emissão e transferência de faturas. Daí dizer Waldirio Bulgarelli que a operação de factoring seria a "venda do faturamento de uma empresa à outra, que se incumbe de cobrá-lo, recebendo em pagamento uma comissão"” (DINIZ, 2011, p. 777).
} 
Parágrafo único. O contrato de fomento empresarial poderá prever, ainda, a prestação de serviços relacionados à atividade empresarial, tais como:

I - assessoria sobre o processo produtivo ou mercadológico; II avaliação e seleção de clientes ou fornecedores;

III - análise e gestão de créditos;

IV - acompanhamento de contas a pagar e a receber.

A atividade de fomento mercantil pode ser exercida livremente pelo empresariado nacional, não sendo regulada por nenhum órgão oficial do governo. Contudo, parte da doutrina classifica o factoring como contrato bancário impróprio,

atribuindo a uma instituição financeira (conceito no art. 17 da lei 4.595/1964) ${ }^{4}$ ou

Banco a necessidade de figurar como o faturizador, conforme entendimento de

Fábio Ulhoa Coelho (2013) ${ }^{5}$ e André Luiz Santa Cruz Ramos (2015) ${ }^{6}$.

Apesar da autoridade dos juristas acima mencionados, não nos filiamos a este entendimento. Afinal, não existe, atualmente, nenhum óbice legal para que a faturização seja praticada por empresários que não exercem atividades bancárias, situação que é conhecida pelos nobres juristas ${ }^{7}$.

O contrato de factoring, apesar de manter semelhanças com o contrato de cessão de crédito e com o contrato de desconto bancário, diferencia-se deles, tornando-se um contrato autônomo, podendo assumir formas ainda mais complexas dependendo da modalidade contratada ${ }^{8}$. Este estudo se ocupa do factoring convencional, explicado por Fabrício Vasconcelos de Oliveira (2006, p. 94):

\footnotetext{
4 “Art. 17. Consideram-se instituições financeiras, para os efeitos da legislação em vigor, as pessoas jurídicas públicas ou privadas, que tenham como atividade principal ou acessória a coleta, intermediação ou aplicação de recursos financeiros próprios ou de terceiros, em moeda nacional ou estrangeira, e a custódia de valor de propriedade de terceiros"

"Faturização - ou "fomento mercantil" - é o contrato pelo qual uma instituição financeira (faturizadora) se obriga a cobrar os devedores de um empresário (faturizado), prestando a estes o serviço de administração de crédito" (COELHO, 2013, p. 518)

6 "Trata-se, enfim, de um contrato por meio do qual o empresário transfere a uma instituição financeira (que não precisa ser, necessariamente, um banco) as atribuições atinentes à administração do seu crédito" (RAMOS, 2015, p. 597).

7 "O banco central já considerou a faturização um contrato bancário pela Res. BC n. 703/82, que foi revogada pela Res. BC n. 1.359/89. Atualmente, portanto, inexiste ato infralegal que vede a exploração da atividade de faturização de créditos a não exercentes de atividade bancária" (COELHO, 2013, p. 520); "[...] o STJ entende que o factoring não possui, de acordo com a Lei 4.595/1964, natureza de contrato bancário típico, razão pela qual, inclusive, as faturizadoras não precisam de autorização do Banco Central para funcionar [...]” (RAMOS, 2015, p. 601).

8 "As principais modalidades de faturização são: factoring convencional, maturity factoring, trustee factoring, factoring para exportação e factoring matéria - prima [...] Maturity factoring é a modalidade de fomento mercantil onde o cliente procura o factor e lhe oferece créditos ainda por vencer. Caso a faturizadora os aceite em cessão, pagará seu valor ao cliente no dia do vencimento mediante uma remuneração [...] No trustee factoring a faturizadora passa a administrar as contas do cliente, assessorando-o na seleção de compradores e na verificação dos riscos, além de comprar créditos decorrentes das vendas. Nesta modalidade, verifica-se a prestação dos serviços diferenciados, por excelência [...] $\mathrm{O}$ factoring para exportação, também conhecido como import - export factoring,
} 
O conventional factoring, também conhecido como old line factoring, factoring tradicional, factoring com antecipação, ou, simplesmente, factoring convencional é a forma mais tradicional ou usual deste contrato. O elemento característico do factoring convencional é que, neste, o cliente procura a faturizadora e lhe oferece créditos ainda por vencer. Caso a mesma aceite a cessão, antecipará ao cliente o valor nele constante, mediante o pagamento de uma remuneração.

Importante também mencionar a lição de Fábio Ulhoa Coelho (2013, p. 519):

[...] Se a instituição financeira garante o pagamento das faturas antecipando o seu valor ao faturizado, tem-se o conventional factoring. Essa modalidade compreende, portanto, três elementos: serviços de administração do crédito, seguro e financiamento.

Nesse caso, apesar da semelhança nos conceitos apresentados, entendemos que o mais adequado é o primeiro, uma vez que no conceito de Fábio Ulhoa Coelho, encontramos duas situações prejudiciais pontuais, quais sejam: 1- a instituição financeira como faturizadora ; 2- o termo "financiamento".

Ora, como dito anteriormente, nada impede que outro empresário que não exerça atividade bancária possa vir a se enquadrar como faturizador; e a palavra financiamento está diretamente ligada à idéia de instituição financeira e contratos bancários, quando na verdade o factoring não realiza financiamentos, mas sim, o que ocorre é verdadeira aquisição remunerada de crédito e prestação de serviços.

$\mathrm{O}$ contrato de cessão de créditos não é o mesmo que o contrato de factoring. $\mathrm{Na}$ verdade, a cessão de créditos pode ser considerada parte do factoring, mas não o todo. $\mathrm{O}$ contrato de factoring é mais amplo, posto que, pode, conforme dito, envolver também a prestação de serviços, como: de assessoria sobre o processo produtivo ou mercadológico, acompanhamento de contas a pagar e a receber, entre outros (RIZZARDO, 2000) ${ }^{9}$.

transcende o âmbito de um Estado, estando ligado ao mercado internacional [...] Nesta modalidade, o cliente de um factor, que exporta mercadorias, lhe transfere créditos em função de seu importador [...] O factoring matéria - prima consiste num mecanismo para facilitar ao cliente o acesso a insumos. Nesta forma de atuação, a faturizada não fomenta recursos financeiros, mas matéria-prima/insumo, adquirida junto ao fornecedor" (OLIVEIRA, 2006, p. 94-97)

9 A respeito desta distinção cabe fazer referência ao que ensina Arnaldo Rizzardo: "Se várias as semelhanças ou até coincidências de tratamento, não engloba a cessão de crédito todo o conteúdo de factoring. Mais amplo o objeto deste último relativamente àquela. Conforme já desenvolvido, não apenas a cessão de títulos de crédito é objeto do factoring. Abrange este instituto mais campos de atuação, ou uma gama de serviços bem ampla, como gestão de crédito e dos negócios de comerciantes, fabricantes e prestadores de serviços, a administração de contas a pagar e a receber, assessoria aos clientes na seleção de riscos até a venda final dos produtos, cobrança de títulos, fornecimento de recursos, saneamento do mercado, otimização da capacidade gerencial do pequeno e médio empresário, além de outras atividades". (RIZZARDO, Arnaldo. Factoring. 2 ed. ver. atual. e ampl. São Paulo: Editora Revista dos tribunais, 2000. P. 40-41) 
Já o desconto bancário, por uma análise perfunctória, pode parecer similar ao contrato de factoring. Entretanto, estes contratos guardam diferenças ainda maiores que as semelhanças, tais como: o factoring é mais complexo que o desconto bancário, uma vez que não se esgota somente com a aquisição onerosa de créditos, mas também envolve prestação de serviços; o desconto bancário é realizado por bancos enquanto que o factoring não é contrato bancário, isto é, não é realizado por instituições financeiras, como ensina Fabrício Vasconcelos de Oliveira (2006) ${ }^{10}$.

Marcelo Negri Soares (2010) atribui a principal diferença entre o contrato de factoring e o desconto bancário ao direito de regresso, de modo que, para o referido jurista, no factoring não existe possibilidade, em regra, de exercer o direito de regresso em face do faturizado, enquanto que no contrato de desconto bancário existe a possibilidade de o banco exercer o direito de regresso em face do descontante-endossatário.

Com o devido respeito, mas não concordamos com tal entendimento. Afinal, se o desconto bancário e o contrato de factoring são contratos atípicos, ou seja, não regulados especificamente por lei, por qual motivo é permitido no desconto bancário o direito de regresso e no contrato de factoring não?

Como veremos adiante, no contrato de factoring existem controvérsias acerca da possibilidade de utilização deste direito pelo faturizador em face do faturizado na doutrina e na jurisprudência do Superior Tribunal de Justiça. O escopo deste trabalho é analisar a jurisprudência do STJ frente à teoria do direito.

\section{O DIREITO DE REGRESSO NO CONTRATO DE FACTORING NA JURISPRUDÊNCIA DO SUPERIOR TRIBUNALDE JUSTIÇA}

Conforme dito, a forma mais conhecida do factoring, a convencional, envolve a aquisição remunerada de crédito entre faturizador e faturizado. Destarte, quando o

\footnotetext{
10 "Em primeiro lugar, o desconto bancário é um contrato real, o qual só se aperfeiçoa com a transferência do crédito ao banco; já a faturização é um contrato consensual [...] $O$ elemento fundamental é a transferência remunerada de um crédito; o fomento mercantil, por outro lado, implica na transferência remunerada de um crédito cumulada com a prestação de serviços [...] $\mathrm{O}$ desconto bancário implica necessariamente na antecipação do valor do crédito cedido; já na faturização, a antecipação do valor do crédito não é obrigatória, dependendo da modalidade avençada pelas partes. Caso seja estipulada a modalidade maturity factoring, o valor do crédito só será repassado ao cliente na data de seu vencimento [...] outro aspecto da maior importância é que o desconto bancário, como se infere de sua própria denominação, é levado a cabo por bancos [...] Após inúmeros debates doutrinários, e, principalmente, após o posicionamento dos tribunais pátrios, firmou-se o entendimento que o fomento mercantil não é atividade bancária" (OLIVEIRA, 2006, p.145-146).
} 
emitente do título, o devedor original, não paga o valor da dívida avençada para o faturizador, que adquiriu o crédito do faturizado, é que surge o conflito acerca da possibilidade de o faturizador voltar-se contra o faturizado, para receber o crédito tendo em vista que a aquisição, na maioria dos casos, se dá mediante endosso e mediante cláusula pro solvendo estipulada no contrato de factoring.

$\mathrm{Na}$ doutrina, a principal corrente entende que no contrato de factoring, não é cabível o direito de regresso do faturizador em face do faturizado, exceto em situações excepcionais, quando, por exemplo, o faturizado atua em conluio com o emitente do título representativo da dívida para levantar de forma ilícita quantia junto ao faturizador.

Neste sentido advoga Marcelo Negri Soares (2010, p. 120-121):

Não existe hipótese de imputar responsabilidade ao faturizado- cedente pelo crédito cedido quando da ocorrência de ausência de liquidação do crédito pelo devedor ou sacado dos títulos cedidos por meio de operação de factoring, salvo se a empresa de factoring comprovar dois requisitos concomitantemente, quais sejam: a) erro escusável na seleção do crédito e, b) má-fé ou dolo por parte do faturizado, que usou de artimanhas ou conluio com os devedores- sacados para aplicar engodo à empresa de factoring, vitimada por orquestração criminosa.

Na mesma linha de raciocínio leciona Arnaldo Rizzardo (2000, p. 85):

Uma vez admitido o direito de regresso, não encontra qualquer justificativa a remuneração ao faturizador. E a remuneração envolve precisamente $o$ quantum correspondente ao risco que assume o factor pelas vicissitudes do crédito, inserindo-se nele a possibilidade de insolvência do devedor. Assim, o crédito é comprado pelo factor, que paga um preço abatido o correspondente ao risco.

Assim, não possui valor, no contrato, cláusulas como as seguintes:

- ' O cedente é responsável solidário com o devedor pelo pagamento do principal e acessórios dos titulos cedidos'.

O Egrégio Superior Tribunal de Justiça nos seus julgados mais recentes vem consolidando o entendimento acima ${ }^{11}$. Vejamos:

DIREITO CIVIL E EMPRESARIAL. CONTRATO DE FACTORING. CESSÃO DE CRÉDITO PRO SOLUTO. ARTS. 295 E 296 DO CÓDIGO CIVIL.

11 Sobre o assunto ver também os seguintes julgados: REsp 949360/RN, Min Antonio Carlos Ferreira, quarta turma, DJe 19/03/2014 ; REsp 1167120/RS, Min. Nancy Andrighi, terceira turma, DJe05/11/2013; AgRG no REsp 1305454/SP, Min. Sidnei Beneti, terceira turma, DJe 14/08/2012. 
GARANTIA DA EXISTÊNCIA DO CRÉDITO CEDIDO. DIREITO DE REGRESSO DA FACTORING RECONHECIDO.

1. Em regra, a empresa de factoring não tem direito de regresso contra a faturizada - com base no inadimplemento dos títulos transferidos -, haja vista que esse risco é da essência do contrato de factoring. Essa impossibilidade de regresso decorre do fato de que a faturizada não garante a solvência do título, o qual, muito pelo contrário, é garantido exatamente pela empresa de factoring.

2. Essa característica, todavia, não afasta a responsabilidade da cedente em relação à existência do crédito, pois tal garantia é própria da cessão de crédito comum - pro soluto. É por isso que a doutrina, de forma uníssona, afirma que no contrato de factoring e na cessão de crédito ordinária, a faturizada/cedente não garante a solvência do crédito, mas a sua existência sim. Nesse passo, o direito de regresso da factoring contra a faturizada deve ser reconhecido quando estiver em questão não um mero inadimplemento, mas a própria existência do crédito.

3. No caso, da moldura fática incontroversa nos autos, fica claro que as duplicatas que ensejaram o processo executivo são desprovidas de causa - "frias" -, e tal circunstância consubstancia vício de existência dos créditos cedidos - e não mero inadimplemento -, o que gera a responsabilidade regressiva da cedente perante a cessionária.

4. Recurso especial provido.

(REsp 1289995/PE, Min. Luis Felipe Salomão, Quarta turma, DJe $10 / 06 / 2014)$

Assim, a corrente majoritária entende não ser possível ao faturizador ou factor exercer direito de regresso contra o faturizado em operação de factoring, sob pena de ficar descaracterizado o contrato, aproximando-se de contrato de desconto, e, portanto, da atividade bancária, bem como pelo fato de que a forma de transmissão do crédito no contrato de factoring se opera por meio de cessão, que no direito brasileiro, em regra, não permite a compra de crédito na modalidade pro solvendo.

Os adeptos deste entendimento afirmam que em caso de haver direito de regresso no factoring, estaria caracterizado como atividade bancária. Os que pensam desta forma sentenciam que o que difere o factoring do contrato de desconto bancário ou de outra operação bancária é justamente pelo fato de que não pode o faturizador valer-se da clausula pro solvendo em contrato de factoring, pois estaria o mesmo atuando no mercado bancário.

Vejamos o entendimento de Marcelo Negri Soares (2010, p. 120-121):

O diferencial na prestação de serviço que resulte em fomento mercantil ou ganho para empresa tomadora é o motivo distintivo determinante, traço característico que o distingue do mero empréstimo com garantias realizado pelas companhias financeiras participantes do Sistema Financeiro Nacional (instituições financeiras) [...] É nulo de pleno direito o contrato que rezar responsabilidade pro solvendo do faturizado, pois estará a empresa de factoring oferendo, na prática, um contrato de desconto de títulos, realizando a cobrança e, se infrutífera, o regresso em conta-corrente mantida perante a faturizadora.

Com devido o respeito, mas entendemos que o fundamento acima apresentado não se sustenta. Ora, já explicamos que o contrato de factoring e o contrato 
de desconto bancário possuem diferenças marcantes. Logo, eventual admissibilidade de uma cláusula pro solvendo num contrato de factoring jamais constituiria atividade bancária, nem tampouco contrato de desconto bancário. Curiosamente, em sentido contrário ao entendimento acima, poderíamos utilizar o mesmo fundamento que possibilita o direito de regresso no desconto bancário para viabilizar também no contrato de factoring. Afinal, sendo ambos contratos atípicos, qual o motivo de ser permitido o direito de regresso no desconto bancário e não no factoring?

Em sentido contrário, admitindo o direito de regresso, juristas de renome admitem possibilidade de o faturizador exercer o direito de regresso em face do faturizado quando houver esta previsão no contrato, seja pela autonomia privada e pelo fato do contrato de factoring ser um contrato atípico, seja pela aplicação das leis específicas de transmissão dos títulos de crédito.

O principal fundamento utilizado em favor do direito de regresso para aqueles que defendem esta possibilidade é justamente: 1- a existência de leis específicas acerca dos títulos de créditos objetos de operação de factoring como a duplicata (lei 5474/68) e o cheque (lei 7357/85), que são transmitidos mediante endosso, que por sua vez torna o endossante garante do pagamento, 2- o fato do factoring ser contrato ser atípico, podendo as partes pactuar livremente nos termos do art. 425 do Código Civil e; 3- No caso de entender ser a transmissão realizada por cessão, estaria permitido por força do art. 296 do Código Civil a clausula pro solvendo, e conseqüentemente, o direito de regresso, sem contar os princípios constitucionais da legalidade e da livre iniciativa.

Neste sentido ensina Waldirio Bulgarelli (2001, p. 545-546):

Já quando se tratar de título de crédito, a cessão se fará pela forma peculiar do direito cambiário, ou seja, o endosso. Neste caso, o factor poderá voltar- se contra o endossante, se o devedor recusar-se a pagar, justamente com base nas causas apontadas no art. $8^{\circ}$ da lei $n^{\circ}$. 5474, de 18-07-1968, ou seja: "o comprador só poderá deixar de aceitar a duplicata por motivo de: I- avaria ou não recebimento das mercadorias, quando não expedidas ou não entregues por sua conta e risco; IIvícios, defeitos e diferenças na qualidade ou na quantidade das mercadorias, devidamente comprovados; III- divergência nos prazos ou nos preços ajustados,..." (casos em que; pelo disposto no art. 16 da recente Lei $n^{\circ} .6458$, de $1^{\circ}$ de novembro de 1977, a ação de cobrança só poderá ser feita pelas vias ordinárias). Contudo, oendosso do título ao factor não será meramente um endosso mandato, mas pleno, transferindo-lhe a propriedade do título; entretanto como é norma em nosso meio, o endossante ficará como garante tanto do aceite como do pagamento, respondendo quer pela veracidade do título (garantia veritas), quer pela realização (garantia bonitas); enfim ficando o factor com o direito de regresso.

Importante registrar a mudança de entendimento de André Luiz Santa Cruz 
Ramos (2015, p. 597-598):

Nas edições anteriores desta obra, defendi que nos contratos de factoring, seja qual for a espécie - maturity ou conventional-, a instituição financeira deveria assumir o risco do inadimplemento dos créditos do faturizado que lhe são cedidos. Eu sustentava que isso distinguia o factoring do desconto bancário, e complementava afirmando que o faturizado, que cede crédito à faturizadora, não deveria responder pela inadimplência dos créditos que cedeu, porque isso contrariaria a própria natureza do factoring. Cheguei a defender, absurdamente, que se deveria desconsiderar eventual endosso praticado no título de crédito cedido, atribuindo-lhe efeito de mera cessão civil de crédito. O tema é deveras controvertido na doutrina. Porém, não é difícil perceber que a posição por mim defendida nas edições anteriores era absolutamente incongruente coma visão liberal que atribuo ao direito empresarial. Portanto, evoluí meu entendimento sobre o assunto [...] $\mathrm{O}$ entendimento de que é possível o direito de regresso, na nossa opinião, deve prevalecer.

Destarte, factoring e desconto bancário não devem ser confundidos, inclusive pelo motivo de que no desconto os recursos que a instituição financeira utiliza são de terceiros (intermediação financeira), enquanto que os recursos dos empresários de factoring são próprios; dada a atipicidade do contrato de factoring, deve prevalecer a autonomia das partes para livremente pactuar; não existe regra nenhuma que impeça a previsão de uma cláusula que permita o direito de regresso ou que afaste os efeitos decorrentes do endosso em caso de inadimplemento (RAMOS, 2015).

Na jurisprudência do Superior Tribunal de Justiça, cabe mencionar uma que teve como relator o, ex-presidente, Ministro Humberto Gomes de Barros, que de forma clara e objetiva decidiu:

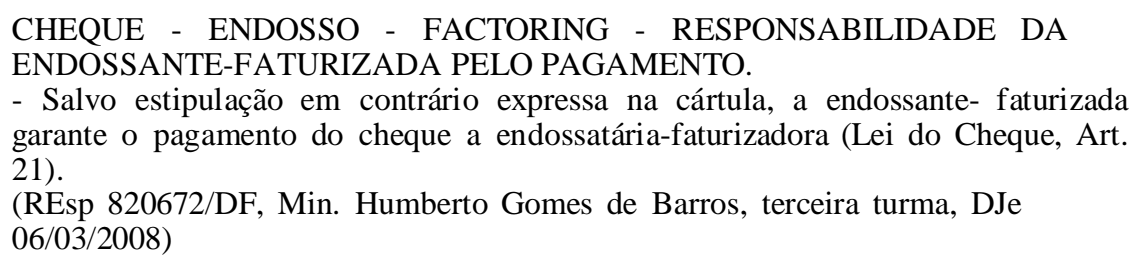

Na oportunidade, o eminente Ministro relator chamou a atenção para o fato de haver jurisprudências, que levam mais em consideração a doutrina do que a própria lei, fonte primária do direito que é.

Cumpre destacar alguns pontos do voto do Eminente Ministro relator no REsp 820672/DF:

[...]Convém relembrar que apesar de já existirem alguns projetos de lei em andamento no congresso nacional, o fomento mercantil não tem regulação própria em nosso país. Assim, sob o ponto de vista legal, as sociedades empresárias de fomento mercantil estão sujeitas aos mesmos direitos e obrigações que qualquer outra sociedade que explore outra atividade empresarial. Não há razão para distinção. Em suma: a exclusão da garantia do endosso às sociedades de fomento mercantil é incompatível com os princípios constitucionais da isonomia, da livre 
iniciativa e da legalidade.[...] Tenho percebido que a jurisprudência tem feito restrições cambiais à atividade de fomento mercantil. Com todo o respeito, não entendo o porquê das limitações feitas a tal atividade empresarial, pois a Lei não as faz.[...] Não se pode perder de vista que a livre iniciativa também é fundamento da República Federativa do Brasil (CF, Art. 1º, IV).

O julgado acima foi preterido pelos julgados que defendem a inexistência do direito de regresso no contrato de factoring. Nesse sentido, surge a indagação acerca do acerto ou não do entendimento atualmente adotado pelo STJ, à luz da teoria do direito.

\section{ANÁLISE DO DIREITO DE REGRESSO NO CONTRATO DE FACTORING NA JURISPRUDÊNCIA DO STJ}

Antes de realizar uma análise da jurisprudência do STJ acerca do direito de regresso nos contratos de factoring, importante entender, sem pretensão de esgotar o debate, alguns aspectos da teoria do direito, como: o que é e como se aplica o Direito e quais são os métodos hermenêuticos que devem ser adotados pelo juiz no momento de decidir.

O direito, conforme postulado de Kelsen (1998), pode ser definido como uma ordem de conduta humana, ou norma jurídica, e pode ser visto na sua forma estática (um sistema de normas em vigor) ou na forma dinâmica (processo jurídico em que o direito é produzido e aplicado).

Nosso estudo se ocupa com Direito na sua forma dinâmica, ou seja, tem como escopo analisar como ele está sendo aplicado pelo Superior Tribunal de Justiça na sua jurisprudência, particularmente nos contratos de factoring e a possibilidade ou não de direito de regresso.

Nessa senda, mister destacar que a lei é fonte primária do ordenamento jurídico brasileiro, nos termos do art. $3^{\circ}$ e $4^{\circ}$, da Lei de introdução às normas do direito brasileiro, que dispõem:

Art. $3^{\circ}$ Ninguém se escusa de cumprir a lei, alegando que não a conhece.

Art. 4ํㅡㄹ Quando a lei for omissa, o juiz decidirá o caso de acordo com a analogia, os costumes e os princípios gerais de direito.

Para aplicar o direito no caso concreto, o juiz deverá valer-se dos elementos de interpretação jurídica adotados no sistema brasileiro, sendo que nenhum destes pode ser manejado isoladamente. São eles: gramatical, histórico, sistemática e teleológica (BARROSO, 2015) e (MENDES e BRANCO, 2015). 
Notadamente, significa dizer que sempre que o magistrado for decidir, deverá obedecer aos comandos da Lei de introdução às normas do direito brasileiro, e, portanto considerar primeiramente sempre a existência de lei para resolver o caso concreto, bem como valer-se conjuntamente dos elementos de interpretação jurídica mencionados para chegar numa decisão adequada.

Consoante Barroso (2015) ${ }^{12}$ e Tartuce (2015) ${ }^{13}$, o Direito no Brasil, sofreu influência da escola denominada Civil Law, de origem romano-germânica, na qual a lei é fonte primária do sistema jurídico. O principio da legalidade encontra-se estampado no art. $5^{\circ}$, inciso II, da Constituição Federal.

A interpretação gramatical está pautada nos conceitos contidos na norma e nas possibilidades semânticas das palavras que integram o seu relato. Em diversos casos, a atividade interpretativa não envolverá complexidades que fujam da aplicação textual dos enunciados normativos. Todavia, em de regra, o intérprete deverá considerar não apenas o texto da lei, devendo buscar a essência e o sentido proveniente da combinação com os outros elementos de interpretação (BARROSO,2015).

A interpretação histórica visa constatar ou resgatar o verdadeiro espírito da norma, contudo nos países de tradição romano-germânica, fica num plano secundário dado o seu caráter subjetivista. Já a interpretação sistemática, está ligada a idéia de harmonia e unidade de um sistema jurídico, devendo todas as normas serem aplicadas em conformidade com a Constituição, conforme Luis Roberto Barroso( 2015).

A interpretação teleológica sustenta-se na constatação de que o direito não é um fim em si mesmo, de modo que todas as normas devem buscar a realização de fins sociais,]

como: dignidade humana, justiça social, bem-estar social, segurança jurídica, entre outros. A interpretação teleológica é constantemente adotada em julgamentos nos tribunais superiores visando o fim último de uma norma (BARROSO, 2015).

\footnotetext{
12 "Nos países de tradição romano-germânica, a principal fonte do Direito são as normas jurídicas escritas" (BARROSO, 2015, p. 326).

13 “O Direito Brasileiro sempre foi filiado à escola da Civil Law, de origem romano-germânica, pela qual a lei é fonte primária do sistema jurídico [...] A conclusão, portanto, é pela permanência, pelo menos por enquanto, de um sistema essencialmente legal. Como é notório, o princípio da legalidade está expresso no art. $5^{\circ}$, inc. II, da Constituição Federal de 1988, pelo qual ninguém será obrigado a fazer ou a deixar de fazer algo senão em virtude da lei” (TARTUCE, 2015, p. 3).
} 
Pois bem, conforme dito anteriormente, o STJ vem adotando o entendimento de que não é cabível direito de regresso nos contrato de factoring. Pergunta-se: referida decisão atendeu os preceitos acima delineados?

Afirmar categoricamente que o contrato de factoring não permite direito de regresso por sua própria natureza, parece-nos ser fundamento extremamente frágil daqueles que querem decidir conforme sua consciência, o que é preocupante.

Conforme Kelsen (1998), a norma deve ser utilizada como um esquema de interpretação. Assim, o sentido jurídico, sua significação jurídica, recebe-a o fato em questão por intermédio de norma que a ele se refere com o seu conteúdo, que lhe empresta a significação jurídica, ou seja, o ato pode ser interpretado segundo esta norma.

Como dito, no Brasil a fonte primária do direito é a lei. Deste modo, deve-se considerar primeiramente que o contrato de factoring é um contrato atípico, ou seja, as regras serão livremente estipuladas pelas partes.

Ora, se não existe lei que proíba estipular direito de regresso no contrato de factoring, qual o fundamento para que um Tribunal indefira tal pleito? A doutrina não pode servir de proteção para decisões eivadas de subjetividade, ideologia ou até mesmo interesses pessoais.

Entendemos que a liberdade de contratar e livremente pactuar a cláusula de regresso pleiteada pelos empresários do ramo de fomento mercantil, consubstanciada numa permissão concedida num dado ordenamento jurídico, é perfeitamente cabível.

Nesse ponto merece destaque a lição de Hans Kelsen (1998, p.46):

Como ordem social que estatui sanções, o Direito regula a conduta humana não apenas num sentido positivo - enquanto prescreve uma tal conduta ao ligar um ato de coerção, como sanção, à conduta oposta e, assim, proíbe esta conduta - mas também por uma forma negativa - na medida em que não liga um ato de coerção a determinada conduta, e, assim, não proíbe esta conduta nem prescreve a conduta oposta. Uma conduta que não é juridicamente proibida é - neste sentido negativo - juridicamente permitida. (grifo nosso).

Nessa linha de raciocínio, o factoring não sofre nenhuma restrição ao direito de regresso em nenhuma lei. Em sentido contrário, existem dispositivos legais que podem perfeitamente permitir a inserção de desta cláusula no contrato.

Se entendermos que o factoring convencional se aperfeiçoa por meio de cessão (que não admite, em regra, direito de regresso), a regra que permitiria que houvesse a cláusula regressiva por meio da aquisição pro solvendo do crédito seria a do art. 296 do código Civil, 
que dispõe: "Salvo estipulação em contrário, o cedente não responde pela solvência do devedor".

Se, por outro lado, entendermos pela transmissão do crédito pelo endosso, nesta possibilidade mesmo que deveria ser permitido o direito de regresso, pelo contido, no art. 21, da Lei 7357/85, que dispõe: "Salvo estipulação em contrário, o endossante garante o pagamento".

Assim, tanto uma forma de transmissão (cessão), como a outra (endosso), abarcam o direito de regresso, cabendo às partes tão somente optar ou não pela inserção desta cláusula num contrato, estando incluso também o contrato de factoring.

Se analisarmos as recentes decisões do STJ sobre o assunto, veremos que os fundamentos apresentados não decorreram dos elementos de interpretação acima apresentados. $\mathrm{O}$ caso pode ser bem resolvido pelos elementos de interpretação gramatical, histórico, sistemático e teleológico sem maiores problemas, mas os eminentes Ministros do STJ optaram por inovar ao superar a lei com fundamentos doutrinários apenas.

O que realmente preocupa é que um dos Tribunais Superiores do Brasil adote postura de modo a descartar a existência de lei que regule um determinado caso, o que pode ser feito (desde que fundamentado), sem apontar relevantes e sólidos fundamentos. E esta postura preocupa e deve ser combatida, como evidencia Streck (2013, p. 25):

\footnotetext{
[...] é necessário lembrar - antes mesmo de iniciar estas reflexões no sentido mais crítico - que o direito não é (e não pode ser) aquilo que o intérprete quer que ele seja. Portanto, o direito não é aquilo que o Tribunal, no seu conjunto ou na individualidade de seus componentes, dizem que é.
}

Destarte, ao analisarmos a possibilidade ou não de direito de regresso nos contratos de factoring na jurisprudência do STJ, à luz das normas existentes no ordenamento jurídico pátrio e da teoria do direito, bem como numa combinação dos elementos jurídicos de interpretação, não conseguimos visualizar outra resposta senão a clara possibilidade de pactuar o direito de regresso nos contratos de factoring, com o devido respeito aos eminentes Ministros do STJ que entendem de forma contrária.

\section{CONSIDERAÇÕES FINAIS}

O contrato de factoring vem se revelando um importante instrumento de circulação de riquezas e de desenvolvimento econômico e social, principalmente por fomentar 
majoritariamente atividades empresariais de micro empresários e empresários de pequeno porte.

Obviamente destes contratos surgem controvérsias e conflitos, assim como qualquer outra relação jurídica, provenientes principalmente da inadimplência por parte do emitente dos títulos que constituíram o crédito.

Esta pesquisa se ocupou do direito de regresso entre faturizador e faturizado. A relevância da pesquisa se deu pelo fato do factoring ser um contrato atípico que em sua maioria utiliza da cláusula de regressiva para conferir maior segurança para o faturizador e também para tornar o custo da transação menos oneroso para o faturizado.

Entretanto, o Superior Tribunal de Justiça, na sua jurisprudência, vem adotando entendimento contrário ao direito de regresso no contrato de factoring por entender, conforme parte da doutrina, que é da essência do factoring assumir o risco da operação, inviabilizando referido pleito.

Analisamos este entendimento fixado na mais atual jurisprudência do STJ à luz da teoria do direito e dos elementos de interpretação jurídica utilizados no direito brasileiro, mas chegamos numa conclusão pela viabilidade do direito de regresso, diferentemente do Superior Tribunal de Justiça.

A preocupação não surge apenas da divergência nos resultados, mas sim, pelo modo como o Tribunal da Cidadania vem estruturando suas decisões, isto é, conforme suas consciências.

Não pretendemos esgotar a discussão sobre o tema, mas revelamos preocupação com o modo como os Tribunais pátrios vêm decidindo, especialmente o STJ. Não podemos perder o rumo e permitir que as decisões sejam dadas com base no argumento da força e não pela força destes, como deveriaser.

\section{REFERÊNCIAS}

AZEVEDO, Álvaro Villaça. Teoria Geral dos contratos típicos e atípicos: curso de direito civil. São Paulo: Editora Atlas, 2002.

BARROSO, Luís Roberto. Curso de direito constitucional contemporâneo: os conceitos fundamentais e a construção do novo modelo. $5^{\mathrm{a}}$ ed. - São Paulo: Saraiva, 2015.

BRASIL. Constituição da República Federativa do Brasil de 1988. Disponível em: <www.planalto.gov.br/ccvil_03/constituicao/constituicao.htm> - acesso em 20/09/2015. 
. Projeto de Lei da Câmara n. 13/2007. Dispõe sobre as operações de fomento mercantil factoring, e dá outras providências. Disponível em: < http://www25.senado.leg.br/web/atividade/materias/-/materia/80244> Acesso em 20/12/2015.

. Lei 4.595, de 31 de dezembro de 1964. Dispõe sobre a Política e as Instituições Monetárias, Bancárias e Creditícias. Cria o Conselho Monetário Nacional e dá outras providências. Disponível em: < http://www.planalto.gov.br/ccivil_03/leis/L4595.htm> Acesso em 03/01/2016.

. Lei 10.406, de 10 de janeiro de 2002. Código Civil. Disponível em: < http://www.planalto.gov.br/ccivil_03/leis/2002/L10406.htm> Acesso em 03/01/2016.

. Lei 9.249, de 26 de dezembro de 1995. Altera a legislação do imposto de renda das pessoas jurídicas, bem como da contribuição social sobre o lucro líquido, e dá outras providências. Disponível em: < http://www.planalto.gov.br/ccivil_03/leis/L9249.htm> Acesso em 22/12/2015.

. Lei 4.657, de 4 de setembro de 1942. Lei de Introdução às Normas do Direito Brasileiro. Disponível em: < http://www.planalto.gov.br/ccivil_03/decreto- lei/Del4657compilado.htm> Acesso em: 17/01/2016.

. Lei 7.357, de 2 de setembro de 1985. Dispõe sobre o cheque e dá outras providências. Disponível em: < http://www.planalto.gov.br/ccivil_03/leis/17357.htm> Acesso em: 17/01/2016.

. Superior Tribunal de Justiça. Recurso Especial 1289995/PE. Disponível em: <https://ww2.stj.jus.br/processo/revista/inteiroteor/?num_registro=201002139690\&dt _publicacao=10/06/2014> Acesso em: 17/01/2016.

. Superior Tribunal de Justiça. Recurso Especial 820672/DF. Disponível em: https://ww2.stj.jus.br/processo/revista/inteiroteor/?num_registro=200600336813\&dt_ publicacao=01/04/2008 Acesso em: 17/01/2016.

BULGARELLI, Waldirio. Contratos Mercantis. 14 ed. - São Paulo: Atlas, 2001. COELHO, Fábio Ulhoa. Manual de direito comercial: Direito de empresa. $25^{\mathrm{a}}$ ed. São Paulo. Saraiva, 2013.

DIAS, Maria Tereza Fonseca; GUSTIN, Miracy Barbosa de Souza (Re) Pensando a pesquisa jurídica: teoria e prática. Belo Horizonte: Del Rey, 2002.

DINIZ, Maria Helena. Curso de direito civil brasileiro, volume 3: teoria das obrigações contratuais e extracontratuais. 27 ed. - São Paulo: Saraiva, 2011.

KELSEN, Hans. Teoria pura do direito. São Paulo: Martins Fontes, 1998. MENDES, Gilmar Ferreira; BRANCO, Paulo Gustavo Gonet. Curso de direito constitucional. 10 ed. rev. e atual. São Paulo: Saraiva, 2015.

OLIVEIRA, Fabrício Vasconcelos de. Factoring e desconto bancário: um estudo comparativo. Leme: BH, 2006. 
RAMOS, André Luiz Santa Cruz. Direito empresarial esquematizado. 5a ed. rev., atual. e ampl. Rio de Janeiro: Forense; São Paulo: Método, 2015.

RIZZARDO, Arnaldo. Factoring. 2 ed. ver. atual. e ampl. São Paulo: Editora Revista dos Tribunais, 2000.

SOARES, Marcelo Negri. Contrato de factoring. $1^{\text {a }}$ ed. São Paulo. Saraiva, 2010. STRECK, Lênio

Luiz. O que é isto - decido conforme minha consciência? - 4 ed.

rev. Porto Alegre: Livraria do Advogado Editora, 2013.

TARTUCE, Flávio. Manual de direito civil: volume único. 5 ed. rev. atual. e ampl. Rio de Janeiro: Forense ; São Paulo: Método, 2015. 